\title{
Familia y jefatura del hogar a finales del reinado de Fernando VII: la ciudad de Trujillo
}

\author{
Family and Heads of Household near the End of the Reign \\ of Fernando VII: The City of Trujillo
}

\section{Raquel Tovar Pulido}

UNIVERSIDAD DE EXTREMADURA, rtovarp@unex.es

En este trabajo se analizan las familias de Trujillo -ciudad de la alta Extremadura-, en los años veinte del siglo xIx. Para abordar esta cuestión, nos valemos de una fuente documental de riqueza excepcional, los padrones de habitantes de la ciudad de Trujillo, que ofrecen listados de familia. De tal manera que, aplicando el método de recomposición de familias -empleado por P. Laslett ya en los setenta-, nos ha sido posible acercarnos a dos importantes variables en la investigación en Demografía Histórica e Historia de la Familia: por un lado, en lo que respecta al conocimiento de los modelos de familia, abordamos la composición interna de los agregados domésticos y los lazos de parentesco que unen a los miembros integrantes de cada hogar; y, por otro, analizamos las características que definen a los hombres y mujeres que se hacen responsables de la jefatura del hogar.

Palabras clave: estructura del hogar, cabezas de familia, Extremadura, Península Ibérica, Antiguo Régimen.

This article analyzes families in the city of Trujillo -in the high Extremadura- in the 1920s. The study is based primarily on a documentary source of extraordinary value: a census of the inhabitants of Trujillo that includes complete listings of every family living there. The family recomposition method applied by P. Laslett in the 1970s allowed us to approach two important variables in the fields of historical demography and family history: first, regarding knowledge of family models, we elucidate the nature of the household aggregates and the kinship ties that exist among their various members; second, the study analyzes the figure and role of the head of household or head of family, whether this position was occupied by a man or a woman.

KeYwORDs: family structure, heads of household, Extremadura, Iberian Peninsula, Old Regime.

Fecha de recepción: 19 de octubre de 2016; Fecha de aceptación: 27 de abril de 2017; Fecha de versión definitiva: 8 de mayo de 2017 


\section{INTRODUCCIÓN ${ }^{\mathrm{I}}$}

T os estudiosos de la Historia de la Familia, historiográficamente, han continuado en la línea de los trabajos a través de los que, ya en la década de los ochenta, Rowland establece dos modelos familiares en Espańa; cada uno se caracteriza por una estructura y unas pautas de asentamiento muy específicas. ${ }^{2}$ Por un lado, en la Península Ibérica se aprecia un predominio del sistema neolocal, que está basado en la familia nuclear; y, por otro, las familias situadas en el norte de Espańa son protagonistas de un sistema patrilocal que está basado en la familia troncal.

Por tanto, mientras el área septentrional espańola presentaba en época moderna un modelo de familia extensa, como sucede presumiblemente en Galicia, Asturias, Vascongadas, Aragón y Cataluña; ${ }^{3}$ la familia nuclear impera en el centro y sur peninsular, territorio que abarca las dos Castillas, Andalucía, Murcia, Valencia y sur de Aragón, así como Extremadura. ${ }^{4}$ Este régimen de residencia neolocal, que caracterizaría al territorio extremeño, implica la disponibilidad de medios económicos por parte de los esposos, para garantizar la subsistencia y establecer una nueva familia, o al menos contar con la promesa o la esperanza futura de disponer de una casa separada de la de sus progenitores. ${ }^{5}$

Como método de análisis para el estudio de la familia, consideramos que es interesante seguir el modelo de recomposición de fa-

${ }^{1}$ Este artículo es fruto de la ampliación de una parte del trabajo presentado por la autora en 2014 en los XLIII Coloquios Históricos de Extremadura, cuyas actas fueron publicadas en 2015: Vid. Raquel Tovar Pulido, "Estructura de la familia en la ciudad de Trujillo a finales del Antiguo Régimen (1824-1825)”, en XLIII Coloquios Históricos de Extremadura: dedicados a Luisa de Carvajal y Mendoza en el IV Centenario de su muerte, ed. VV. AA. Trujillo, del 22 al 28 de septiembre de 2014, 2015, 869-886.

${ }^{2}$ Robert Rowland, "Sistemas matrimoniales en la Península Ibérica (siglos XVI-XIX). Una perspectiva regional”, en La demografía histórica en España, ed. Vicente Pérez Moreda y David S. Reher, 72-137 (Madrid: El Arquero, 1988).

${ }^{3}$ José Pablo Blanco Carrasco, Demografía, familia y sociedad en la Extremadura moderna, 1500-1860 (Cáceres: Universidad de Extremadura, 1999), 287.

${ }^{4}$ Felicísimo García Barriga, Familia y sociedad en la Extremadura rural de los tiempos modernos (siglos XVI-XIX) (Cáceres: Universidad de Extremadura, 2009), 123-124.

${ }^{5}$ Blanco Carrasco, Demografia, 287. 
milias que, desde finales de la década de los sesenta y principios de los setenta del siglo xx, ${ }^{6}$ fue utilizado por P. Laslett ${ }^{7}$ y el grupo constituido en torno a la Escuela de Cambridge. ${ }^{8}$ Por el gran valor de sus aportaciones, se ha convertido en el método utilizado tradicionalmente por la historiografía, para el conocimiento de la estructura del hogar a partir de las unidades de corresidentes.

El valor de la fuente que hemos analizado para este trabajo es excepcional. Los padrones de habitantes fueron emitidos por la administración municipal y proporcionan la relación de habitantes por edad, sexo y estado civil. ${ }^{9}$ Son listas nominativas que permiten distinguir los hogares entre sí, así como ofrecen información acerca de las relaciones de parentesco entre los individuos que componen el hogar. ${ }^{10}$ Ello nos permite detectar el número de familias que forman parte de cada hogar, ya que en ocasiones puede haber más de una familia residiendo bajo el mismo techo. ${ }^{11}$

Para el presente estudio entendemos por familia aquella que integra el matrimonio o el cónyuge superviviente, en el caso de los viudos, y los hijos que residen en el hogar paterno; así como también forman una familia los viudos sin hijos e individuos aislados,

${ }^{6}$ Francisco García González, "Las estructuras familiares y su relación con los recursos humanos y económicos", en Familias. Historia de la sociedad española (del final de la Edad Media a nuestros días), dir. Francisco Chacón y Joan Bestard, 164 (Madrid: Cátedra, 2011).

${ }^{7}$ Peter Laslett, "La famille et le ménage: approches historiques", Annales, ESC. (4-5) (1972): 847-872.

${ }^{8}$ Peter Laslett, "Introduction: the History of the Family", en Household and Family in Past Time, ed. Peter Laslett y Richard Wall, 1-90 (Cambridge: Cambridge University Press, 1974).

${ }^{9}$ Recogen también información sobre las profesiones, lo que permite reconstruir la estructura socioproductiva de la ciudad. Sobre los oficios en Trujillo en la misma cronología que es objeto de estudio puede consultarse el siguiente trabajo: Raquel Tovar Pulido, "Mercado laboral en un núcleo urbano de la España de finales del Antiguo Régimen: La ciudad de Trujillo", Chronica Nova: Revista de Historia Moderna de la Universidad de Granada, Ejemplar dedicado a: Relaciones entre la Monarquía Hispánica y la Roma Pontificia (siglos XVI y XVII) (42) (2016): 367-397.

${ }^{10}$ En el presente estudio hemos manejado un total de seis Padrones de vecinos, que fueron realizados en los veinte del siglo XIX en la ciudad de Trujillo. Archivo Municipal de Trujillo (амт), Padrones de 1824, 1825, 1826, 1827, 1828 y 1829. Legajo 1004.

${ }^{11}$ Louis Henry, Manual de demografía histórica (Barcelona: Crítica, 1983): 30-38. 
por tanto, la familia es el grupo de personas que corresiden. Asimismo, el hogar se interpreta como el lugar material en el que se acoge a la familia, es decir, la casa. ${ }^{12}$ No obstante, el concepto de hogar historiográficamente también ha sido atribuido a aquellos miembros de la familia que guardan relación de parentesco consanguínea $\mathrm{o}$ artificial, por tanto, padres, hijos y parientes ascendientes, descendientes o colaterales. ${ }^{13}$

La potencialidad de la investigación microanalítica plantea la posibilidad de captar con mayor precisión la complejidad y la multiplicidad de factores que actúan en el funcionamiento del sistema de reproducción familiar, ${ }^{14}$ objetivo último que perseguimos a través de este trabajo.

Nuestro marco cronológico (1824-1829) comprende los años finales de la monarquía de Fernando VII. Después del breve paréntesis al absolutismo borbónico, durante el Trienio Liberal (18201823); inmediatamente después, la Década Ominosa (1823-1833) culminará en el final del Antiguo Régimen en España. ${ }^{15}$

La ciudad de Trujillo, en la década de los veinte del siglo XIX, experimenta una transformación en un plano administrativo, que marcará un antes y un después para la que fue una de las ciudades más importantes de Extremadura durante la época moderna. Desde el siglo Xvi se había convertido en la capital de la provincia de Trujillo -que había sido creada en 1528 y pertenecía a la por entonces

${ }^{12}$ Carmen Hernández López, "La casa en La Mancha Oriental a finales del Antiguo Régimen”, Cuadernos de Historia Moderna (38) (2013): 94.

${ }^{13}$ Francisco Chacón Jiménez, "Familia y hogar en la sociedad española: mitos y realidades históricas", en La familia en la historia, coord. Francisco Javier Lorenzo Pinar, 23 (Salamanca: Universidad de Salamanca, 2009). En este trabajo incluimos dentro de las familias y hogares también a los criados. Un ejemplo es un modelo familiar sin estructura y que está formado por un cabeza de familia y sus criados.

${ }^{14}$ Francisco García González, "Introducción. De la Tierra a la Historia de la Familia en la España meridional”, en Tierra y familia en la España meridional. Siglos XIII-XIX, ed. Francisco García González, 17 (Murcia: Universidad de Murcia, 1998b).

${ }^{15}$ En el plano económico, hemos de tener en cuenta que, en 1817, Extremadura había sufrido una fuerte crisis agraria, que se suma al estancamiento productivo y comercial que arrastraba la región desde el inicio de la Guerra de la Independencia y que continuó hasta los años treinta. Juan García Pérez, "La economía extremeña durante la crisis del antiguo régimen y el tiempo del liberalismo clásico (1808-1874)", Revista de Estudios Extremeños LXIX (I) (2013): 212-219. 
Corona de Castilla- y en ella estaba incluido la mayor parte del territorio que hoy forma parte de la región de Extremadura.

Sin embargo, casi tres siglos más tarde, en 1810, fruto de las invasiones francesas se divide de manera provisional la provincia de Trujillo, en las prefecturas de Cáceres y Mérida; sería el preludio de la división provincial del territorio extremeño en las actuales provincias de Cáceres y Badajoz, que tuvo lugar en 1822 y que tampoco sería definitiva. ${ }^{16}$ Fue entonces cuando la ciudad de Trujillo quedó incluida en la provincia de Cáceres, con el consiguiente final de su supremacía sobre el territorio extremeño. Tendrá que conformarse con continuar siendo capital del Partido de Trujillo, una organización administrativa de tipo tributario, que únicamente abarca las poblaciones de la Extremadura Oriental y que existía desde finales del siglo XVIII. ${ }^{17}$

Son estas circunstancias político-administrativas las que nos llevan a elegir Trujillo como marco geográfico para el estudio de sus familias, dada su importancia no sólo en el periodo cronológico objeto de análisis, sino durante todo el Antiguo Régimen.

\section{LOS MODELOS DE FAMILIA}

En el marco cronológico que abarcamos en nuestra investigación, el casco urbano de la ciudad de Trujillo experimenta un crecimiento positivo en el número de residentes. Los padrones recogen en los primeros años analizados a una población de alrededor de 2,700

${ }^{16}$ Habrá que esperar a 1833 y el final del reinado de Fernando VII, para que se ponga en funcionamiento el sistema administrativo provincial, que fue suprimido desde 1823, con la vuelta al absolutismo. Fernando Sánchez Marroyo, "Estructura políticoinstitucional de Extremadura (1808-1874)", Revista de Estudios Extremeños LXIX(I) (2013): 144-162.

${ }^{17}$ A fines del siglo xvinI, Trujillo es uno de los ocho partidos con los que contaba Extremadura y que funcionaban como subdelegaciones de renta. Asimismo, la complejidad administrativa de Trujillo, a lo largo de la época moderna, hace que resulte difícil acotar su organización político-administrativa. En el siglo XVI se tiene constancia de la existencia de un Partido de Trujillo, con otras demarcaciones geográficas de mayor envergadura, que formaba parte de la provincia de Salamanca. Del mismo modo, en 1822 se crea el denominado Partido Judicial de Trujillo, pero que es suprimido con la restauración del absolutismo. Sánchez Marroyo, "Estructura político-institucional”, 147-151. 
habitantes, que crece a unas 2,900 almas a finales de la década. ${ }^{18}$ Asimismo, hemos procedido al análisis del total de familias que figuran en los recuentos entre 1824 y 1829 ; su número varía cada año y oscila entre 721 y 809 familias. ${ }^{19}$ No obstante, no se observa un aumento en el número de familias paralelo al crecimiento de la población, ya que dicha nueva población pasa a ser incluida en núcleos familiares ya existentes. ${ }^{20}$

Aunque como se señaló en el apartado introductorio, hemos tomado como referencia los modelos planteados por el Grupo de Cambridge ${ }^{21}$ no agrupamos únicamente a las familias a través de las categorías básicas tradicionales. Pues, además, hemos subdividido dichas categorías en varios grupos; ${ }^{22}$ en estos subgrupos, hemos optado por incorporar alternativas, que están encaminadas a indicar de manera detallada qué miembros constituyen cada unidad familiar.

Como veremos, en el sexenio comprendido entre 1824 y 1829 , en Trujillo se producen algunas variaciones respecto al modelo de

${ }^{18}$ Las cifras totales por anualidades son las siguientes: 2,715 habitantes en 1824 , 2,742 en 1825, 2,808 en 1826, 2,772 en 1827, 2,864 en 1828 y 2,923 habitantes en el año 1829. En el recuento no hemos incluido a la población que habitaba en los arrabales, puesto que nuestro trabajo se ha centrado únicamente en las familias de la propia ciudad. El padrón de Trujillo de 1825 indica que contaba con tres arrabales: Huertas de Ánimas, la Magdalena y Belém, donde residían en conjunto 427 vecinos. No obstante, en la actualidad se incluye también un cuarto arrabal, Pago de San Clemente. Se trata de colaciones de tipo rural que se encuentran a varios kilómetros de la ciudad, pero dependen de ella administrativamente. Si Trujillo crece en seis años en 200 habitantes, la ciudad de Coria experimenta un aumento de 300 habitantes entre 1823 (1,469 habitantes) y 1829 (1,773 almas). Vid. José Pablo Blanco Carrasco, Demografía, 454 y 464 . El crecimiento de Trujillo pudo verse frenado por la inestabilidad política y el tránsito de efectivos militares experimentado en la ciudad a finales de la década.

${ }^{19}$ La distribución del número de familias anualmente es la siguiente: 721 familias en 1824; 784 en 1825; 809 en 1826; 786 en 1827; 775 en 1828; y 783 familias en 1829. Por tanto, observamos más familias en los años centrales de la década y no en los años finales, como sería de esperar, ya que la población crece.

${ }^{20}$ No se experimenta un crecimiento de la nupcialidad, lo que explica que no se haya producido un crecimiento del número de familias. El crecimiento de la población se debe a que se produce un incremento en el número de nacimientos. Además, llegan a la ciudad individuos solos (parientes y criados) que pasan a formar parte de las familias existentes.

${ }^{21}$ Laslett, "Introduction: the History", 1-90.

22 Blanco Carrasco, Demografía, 284. 
familia en uno y otro año, si bien, en general, los parámetros son los mismos. ${ }^{23}$

\section{La familia simple: un único núcleo en el hogar}

El modelo de familia que predomina en esta ciudad es el que está constituido por una familia simple, formada por un único núcleo familiar. Es un modelo de hogar del que forman parte $82.82 \%$ de las familias de la muestra analizada.

Este único núcleo familiar, en la mayor parte de los casos, está constituido por padres e hijos y es el modelo de hogar que conocemos como familia nuclear simple. No obstante, los mecanismos de solidaridad familiar podían conducir a la corresidencia de la pareja conyugal y la descendencia de éstos con parientes de distinto grado de consanguinidad que carecieran de otros medios para subsistir, así como la disponibilidad de recursos económicos explicaría la presencia en el hogar de individuos que desempeñan una función laboral; hablaríamos entonces de familia extensa.

\section{La familia nuclear simple}

La familia nuclear simple (tipo 3.1. en la tabla 1) está integrada por padres e hijos y afecta a $66.51 \%$ del total de familias. Entre ellas predominan aquellas que están constituidas por la pareja conyugal y su descendencia (43.25\%) (tipo 3.1.a). Por su parte, la pareja conyugal sin hijos representa $17.63 \%$ de los hogares (tipo 3.1.b); se trata de parejas cuyos hijos no residen en el hogar, así como matrimonios que, bien por su juventud o bien por circunstancias biológicas o de cualquier otra índole, no han tenido descendencia. En ambos casos (tipos 3.1.a y 3.1.b), los resultados obtenidos nos han permitido establecer una comparación del modelo de familia de esta

${ }^{23}$ En el decenio absolutista en el que nos encontramos (1823-1833) pervive la esencia política y social del Antiguo Régimen y la inestabilidad generada por liberales y realistas en España es visible en la ciudad de Trujillo. En Francisco Javier Pizarro Gómez, Arquitectura y urbanismo en Trujillo (siglos XVIII y XIX) (Cáceres: Universidad de Extremadura 1987), 149. 
ciudad alto extremeña en el primer tercio del siglo XIX con poblaciones castellano-manchegas como la ciudad de Alcaraz a finales de la centuria anterior, que en 1787 contaba con un $63.8 \%$ y un $16.5 \%$ de parejas con hijos y parejas sin hijos respectivamente. ${ }^{24}$

Buen ejemplo de ambos modelos de familia es el matrimonio trujillano formado por el hortelano Gabriel Ximénez y su esposa Juana Alía, que residían solos en 1827 en la calle Garciaz y tenían 31 y 21 ańos respectivamente. Sin embargo, observamos que dos años después han tenido descendencia y residen en la misma casa junto a su hijo Manuel. ${ }^{25}$ De modo que aunque continúan siendo una familia nuclear simple, vemos cómo las características internas del hogar han cambiado.

En los tipos de familia nuclear simple también están incluidos los hogares formados por viudos con hijos (4.8\%) (tipo 3.1.c); en ellos el número de mujeres viudas es superior al de varones, un $2.8 \% \mathrm{y}$ $1.9 \%$ respectivamente. Las familias incompletas, resultado de la viudez de uno de los miembros de la desaparecida pareja conyugal, van a caracterizar a las sociedades preindustriales, como "consecuencia de sus mortíferas estructuras demográficas" ${ }^{26}$ Cuando el esposo fallecía, la situación familiar de la viuda se complicaba en gran medida, ya que debía ocuparse en soledad del cuidado del hogar y de la crianza de los hijos, a menudo de corta edad. En algunos casos, la presencia en el hogar de un hijo mayor en edad de trabajar haría posible una contribución económica al mantenimiento del hogar, si bien, esta protección finalizaba cuando el hijo varón contraía matrimonio. ${ }^{27}$

Un ejemplo ilustrativo de este modelo de familia es el que, en 1825 , protagoniza María Muñoz, de 67 años. Figura como viuda y

${ }^{24}$ Francisco García González, La sierra de Alcaraz en el siglo XVIII: población, familia y estructura agraria (Albacete: Instituto de Estudios Albacetenses "Don Juan Manuel", 1998a), 208.

${ }^{25}$ AMt, Padrón de 1827 y Padrón de 1829. Leg. 1004.

${ }^{26}$ Ramón Lanza García, Población y familia campesina en el Antiguo Régimen, Liébana, siglos XVI-XIX (Santander: Universidad de Cantabria, 1988), 139.

${ }^{27}$ María Ángeles Hernández Bermejo, "Estructuras familiares y sistemas de transmisión patrimonial en Extremadura. La ciudad de Coria en el siglo xvıII", en Tierra y familia en la España meridional. Siglos XIII-XIX, ed. Francisco García González, 144 (Murcia: Universidad de Murcia, 1998). 
pobre y reside en la calle Encarnación junto a su hijo de 24 ańos, José Barrantes. En cambio, éste ejerce el oficio de jornalero, lo cual implicaría esa contribución económica a la que nos referimos, que reduciría el estado de pobreza del cabeza de familia. ${ }^{28}$

El cuarto subgrupo de familia nuclear simple es el de hogares constituidos por casados y casadas con hijos (tipo 3.1.d), en los que uno de los miembros de la pareja conyugal se encuentra ausente $(0.55 \%)$. Tampoco son muy numerosos los hogares integrados por mujeres solteras con hijos (0.16 \%) (tipo 3.1.e), mientras que no hemos localizado ningún caso de varones solteros con descendencia. En conjunto, solteras y casados con hijos no llegan a $1 \%$ de las familias ( $0.7 \%$ en conjunto).

El predominio de la familia de tipo nuclear simple en la ciudad de Trujillo es comparable al de otras zonas de la Espańa meridional varias décadas antes. Si en 1787 en el territorio de la jurisdicción de Alcaraz y sus aldeas la familia nuclear representa a $83 \%$ de las familias $^{29}$ y $80.71 \%$ únicamente en la ciudad, ${ }^{30}$ en 1791 afecta en la huerta valenciana, concretamente en la localidad de Meliana, a $71.02 \%$ de las familias. ${ }^{31}$

En el territorio extremeño, a partir de datos de cronología anterior, observamos que la familia nuclear en la ciudad de Coria, entre 1753 y 1761, también es la más frecuente, si bien afecta a un porcentaje menor de hogares, el $48.7 \%$ y $54.5 \%$ respectivamente; ${ }^{32}$ frente a $66.51 \%$ observado en Trujillo entre 1824 y $1829 .{ }^{33}$ Asimismo, los

${ }^{28}$ AMT, Padrón de 1825. Leg. 1004.

${ }^{29}$ Francisco García González, "Labradores, jornaleros y sirvientes en la sierra. Organización doméstica y ciclo de vida (Alcaraz, 1753-1787)", en Tierra y familia en la España meridional. Siglos XIII-XIX, ed. Francisco García González, 163 (Murcia: Universidad de Murcia, 1998c).

${ }^{30}$ García González, La sierra, 208.

${ }^{31}$ Estrella Garrido Arce, "Tener o no tener en 1791. Estructuras familiares y tenencia de la tierra en la Huerta de Valencia, siglo Xvıı", en Tierra y familia en la España meridional. Siglos XIII-XIX, ed. Francisco García González, 207 (Murcia: Universidad de Murcia, 1998).

${ }^{32}$ Hernández Bermejo, "Estructuras familiares”, 143.

${ }^{33} \mathrm{Al}$ analizar la organización del hogar de la ciudad de Trujillo, como se ve en la tabla 1, hemos optado por desagrupar la organización de las familias nucleares en familias nucleares simples y extensas, pues, además establecemos una categoría independiente 
datos de cronología posterior estiman una media para toda Extremadura de $69.2 \%$, a partir de una muestra representativa en la primera mitad del siglo xxx; $3^{34}$ mientras que en 1840 la ciudad castellano-manchega de Cuenca contaba con un $72.2 \%$ de familias nucleares. ${ }^{35}$

En lo que respecta al norte peninsular, en Liébana la familia nuclear simple suponía $65.15 \%$ de las familias en $1752 .{ }^{36}$ Los estudios realizados para otros territorios del norte peninsular desvelan un modelo de familia nuclear que afecta en las mismas proporciones a los núcleos urbanos gallegos, en cuyas ciudades los porcentajes oscilan entre $65.5 \%$ (Santiago y Pontevedra) y $66.4 \%$ (Orense), de acuerdo a los datos proporcionados por Pérez García ${ }^{37}$ para mediados del siglo XVIII. ${ }^{38}$

Observamos que las ciudades extremeñas responden a un mismo modelo de familia, que difiere a la baja de la cuantía de familias nucleares existentes en la ciudad y en la comarca de Alcaraz, así como el levante peninsular. Sin embargo, refleja una continuidad en lo que respecta a la formación de las familias en el interior peninsular y norte de Espańa, el mundo urbano y el mundo rural, en los siglos XVIII y XIX.

Por tanto, el marco geográfico en el que se localiza Trujillo se caracteriza por un sistema familiar de tipo neolocal, en el que cada matrimonio genera una nueva familia, ya que los esposos tradicionalmente inician su residencia en común en una casa independiente de la de los progenitores, lo cual explica el predominio de la familia nuclear simple.

que recoge a las familias múltiples. Pues bien, los datos aportados por los autores mencionados hacen referencia a familias nucleares y familias extensas únicamente, de manera que cuando hablamos de familia nuclear en esta comparativa nos referimos a la familia nuclear simple.

${ }^{34}$ Blanco Carrasco, Demografía, 291.

${ }^{35}$ Francisco García González, "La historia de la familia en el interior castellano: estado de la cuestión y esbozo bibliográfico", en La historia de la familia en la Península Ibérica, siglos XVI-XIX: balance regional y perspectivas. Homenaje a Peter Laslett, ed. Francisco García González, 277-330 (Cuenca: Universidad de Castilla La Mancha, 2008).

${ }^{36}$ Lanza García, Población, 138-139.

${ }^{37}$ José Manuel Pérez García, "Familias y hogares en Galicia y en la Cornisa Cantábrica durante el Antiguo Régimen", en Historia de la familia en la Península Ibérica: balance regional y perspectivas. Homenaje a Peter Laslett, coord. Francisco García González, 60-61 (Cuenca: Universidad de Castilla La Mancha, 2008).

${ }^{38}$ García González, "Las estructuras”, 182. 
Tabla I. Modelos de familia en la ciudad de Trujillo (1824-1829). Tipos de Cambridge. Valores relativos

\begin{tabular}{lc}
\hline Modelos de familia & Porcentajes \\
\hline 1. Solitarios & 11.26 \\
1.a Viudos & 2.11 \\
1.a.aViudas & 5.89 \\
1.b Solteros & 2.29 \\
1.b.a Solteras & 1.11 \\
1.c Casados & 0.50 \\
1.c.a Casadas & 0.24 \\
2. Sin estructura familiar & 4.35 \\
2.a Hermanos & 0.82 \\
2.b Hermanos y criados & 0.05 \\
2.c Cabeza de familia y criados & 2.40 \\
2.d Otros lazos (misma edad, distintos apellidos...) & 0.16 \\
2.e Cabeza de familia y parientes & 1.05 \\
2.f Cabeza de familia, criados y parientes & 0.10 \\
& \\
3. Familia simple (núcleo único) & 82.82 \\
3.1. Familia nuclear simple & 66.52 \\
3.1.a Pareja conyugal sin hijos & 17.64 \\
3.1.b Pareja conyugal con hijos & 43.26 \\
3.1.c.Viudo con hijos & 1.92 \\
3.1.c.a. Viuda con hijos & 2.85 \\
3.1.d. Casada con hijos & 0.39 \\
3.1.d.a. Casado con hijos & 0.16 \\
3.1.e. Soltera con hijos & 0.16 \\
3.2. Familia extensa & 18.48 \\
3.2.a Pareja conyugal, hijos y parientes & 0.06 \\
3.2.b Pareja conyugal, hijos y criados & 0.03 \\
3.2.c Viuda, hijos, criados y parientes & 0.03 \\
3.2.d Colateral (matrimonio y parientes) & 2.48 \\
3.2.e Descendente y colateral (pareja conyugal, hijos, ascendentes & 4.08 \\
y parientes) & \\
&
\end{tabular}


TAbla I. Modelos de familia en la ciudad de Trujillo (1824-1829). Tipos de Cambridge. Valores relativos

Modelos de familia

Porcentajes

3.2.f Descendente y criados

4.72

3.2.g Colateral (pareja conyugal y sobrinos) y criados

3.2.h Descendente y colateral (pareja conyugal, hijos, ascendentes, parientes) y criados

3.2.i Colateral (pareja conyugal y criados)

4. Familia múltiple (más de un núcleo)

4.1. Familia múltiple

4.1.a Colateral (pareja conyugal y sobrinos)

4.1.b Descendente y colateral (pareja conyugal, hijos, ascendentes y parientes)

4.1.c Descendente y criados

4.1.d Colateral (pareja conyugal y sobrinos) y criados

4.1.e Colateral (pareja conyugal y criados)

Total 100

Fuente: Archivo Municipal de Trujillo, AMT, Padrones de 1824 a 1829, leg. 1004. Elaboración propia.

\section{La familia extensa}

Como hemos anunciado en párrafos anteriores, en ocasiones a esta estructura familiar simple se incorporan otros individuos, bien parientes cercanos de tipo ascendente, descendente o colateral; o bien individuos cuyos lazos con el cabeza de familia deriven de cualquier otra condición, tal y como sucedía con el personal doméstico residente en buena parte de las familias de la ciudad. En cualquier caso, se produciría una transformación de familia nuclear simple a familia extensa (tipo 3.2. en tabla 1), de la que forman parte $18.48 \%$ de las familias estudiadas.

Hemos desglosado el modelo de familia extensa en nueve subgrupos, como puede verse en la tabla 1. En ellos diferenciamos los componentes de cada familia y vemos si en la familia reside la 
pareja conyugal o únicamente un viudo, acompańado de hijos, parientes o criados. De la misma manera, cuando se produce la acogida de parientes, distinguimos entre aquellos que son de tipo ascendente, como los padres y abuelos; descendente, los hijos; y colateral, donde incluiríamos a los sobrinos, primos y tíos, así como a personas con o sin vinculación consanguínea con el cabeza de familia, pero que también residen en la misma casa.

Representan muy bien el modelo de familia extensa los Pinto López. Residía en la calle Tintoreros, en 1828, el celador de montes de 55 años Felipe Pinto, que ejercía como cabeza de familia en un hogar en el que corresidían con él su esposa Isabel López, su hija María, su suegra Rosa Asturias, viuda de 75 años, y su cuñado Francisco López, soltero de 45 años. ${ }^{39}$

La complejidad en la que se ven inmersas las familias trujillanas no es observada en igual medida en otras ciudades del mediodía peninsular a finales del Antiguo Régimen, donde su representación es más reducida. En aquellos territorios que Mikelarena ${ }^{40}$ considera parte integrante de la Espańa nuclear, ${ }^{41}$ generalmente, la familia extensa no superaba $10 \%$ de los hogares y cuando esto sucedía los valores se mantenían por debajo de los obtenidos en la ciudad objeto de nuestro interés.

En los estudios realizados sobre poblaciones murcianas, los trabajos de Chacón Jiménez, ${ }^{42}$ Hurtado Martínez, ${ }^{43}$ Sancho Alguacil ${ }^{44}$

${ }^{39}$ AMT, Padrón de 1824 al 1829. Leg. 1004.

${ }^{40}$ Fernando Mikelarena Peña, "Estructuras familiares en España y en Navarra en los siglos XVIII-XIX: factores etnoculturales, diferenciación socioeconómica y comportamientos estratégicos", en Actas II Congreso Italo-Ibérico de Demografía Histórica (Savona, 1992), 20-33.

${ }^{41}$ García González, La sierra, 207.

${ }^{42}$ Francisco Chacón Jiménez, Historia social de la familia en España (Alicante: Instituto de Cultura "Juan Gil-Albert", 1990).

${ }^{43}$ José Hurtado Martínez, "Familia y propiedad: análisis del hogar y de la estructura de la propiedad en Lorca (1771)”, en Familia y sociedad en el Mediterráneo Occidental. Siglos XV-XIX, ed. Francisco Chacón Jiménez, 301-334 (Murcia: Universidad de Murcia, 1987).

${ }^{44}$ Remedios Sancho Alguacil, "Población y estructura familiar en una comunidad de la Vega Alta del Segura: Cieza durante el siglo Xvin”, en Familia y sociedad en el Mediterráneo Occidental. Siglos XV-XIX, ed. Francisco Chacón Jiménez, 279-300 (Murcia: Universidad de Murcia, 1987). 
y Montojo ${ }^{45}$ han desvelado que la existencia de hogares complejos en esta zona del mediodía peninsular afectaba a menos de $5 \%$ de las familias. Los resultados obtenidos por Martín Galán ${ }^{46}$ de una muestra toledana señalan un $13.8 \%$ a finales de la centuria, mientras que en Logroño ${ }^{47}$ y en Granada ${ }^{48}$ las familias extensas suponen entorno a un $12 \%$ y $15 \%$ respectivamente. En la ciudad de Alcaraz, los hogares complejos en 1787 suponían un $6.71 \%$ de las familias ${ }^{49} y$, en la huerta valenciana, las familias extensas en Meliana constituían $10.28 \%$ en $1791 .{ }^{50}$ Este tipo de familias en el norte peninsular durante el siglo XvIII es menos frecuente, por ejemplo, Liébana contaba con un $5.81 \%$ de familias extensas en $1752 .^{51}$

Por tanto, la representatividad de las familias extensas en Trujillo, durante el primer tercio del siglo XIX, adquiere rasgos que advierten de la existencia en esta ciudad de mecanismos de solidaridad familiar de mayor intensidad que los existentes en el interior peninsular durante el siglo XviII.

Por su parte, en el siglo xix los porcentajes de hogares complejos de la Vizcaya urbana, constituida por villas y por Bilbao, oscilan entre $15 \%$ y $20 \%$ en $1825,{ }^{52}$ de acuerdo a los estudios realizados por Arbaiza, ${ }^{53}$ de modo que se aproximan a los de Trujillo. En cam-

${ }^{45}$ Vicente Montojo Montojo, "Rasgos de la estructura familiar en Fuente Álamo (Murcia) a mediados del siglo XviII", en Casa, familia y trabajo. Actas del Congreso Internacional Historia de la Familia. Una nueva perspectiva sobre la sociedad europea, ed. Francisco Chacón Jiménez y Llorenç Ferrer i Allós, 289-295 (Murcia: Universidad de Murcia, 1997).

${ }^{46}$ Manuel Martín Galán, "La población de Madrid y Castilla-La Mancha según el censo de Floridablanca”, en La población española en 1787, II Centenario del censo de Floridablanca, coord. Francisco Chacón Jiménez, 185 (Madrid: Instituto Nacional de Estadística, 1992).

${ }^{47}$ Mercedes Lázaro Ruiz, La población de la ciudad de Logroño durante el Antiguo Régimen (Logrońo: Instituto de Estudios Riojanos, 1994), 259.

${ }^{48}$ James Casey y Bernard Vincent, "Casa y familia en la Granada del Antiguo Régimen”, en La familia en la España mediterránea. Siglos XV-XIX, coord. James Casey et al., 177 (Barcelona: Crítica, 1987).

${ }^{49}$ García González, La sierra, 208.

${ }^{50}$ Garrido Arce, “Tener o no”, 207.

${ }^{51}$ Lanza García, Población, 138-139.

${ }^{52}$ García González, "Las estructuras”, 181-182.

${ }^{53}$ Mercedes Arbaiza Vilallonga, Familia, trabajo y reproducción social: una perspectiva microhistórica de la sociedad vizcaina a finales del Antiguo Régimen (Bilbao: Universidad del País Vasco, 1996), 82-85. 
bio, la representatividad de la familia extensa en el mediodía peninsular es equiparable a la de la centuria anterior, pues, en 1840 la ciudad de Cuenca contaba con un $10.4 \%$ de familias extensas. ${ }^{54}$

Tal diferenciación entre ciudades, en cuanto a la presencia de familias extensas evidencia, por un lado, la existencia de mecanismos de solidaridad familiar más fuertes en la ciudad de Trujillo; y, por otro lado, una posición económica capaz de mantener en el hogar a personas con distinto grado de parentesco, así como sin ningún tipo de lazo consanguíneo.

\section{La familia múltiple: varios núcleos en el hogar}

Además de las familias simples constituidas por un único núcleo familiar, hemos detectado hogares en los que, además del núcleo principal constituido por el cabeza de familia y, en su caso, su cónyuge y los hijos, existe un núcleo secundario formado por una nueva pareja conyugal, que en ocasiones está acompañada de descendencia.

Cuando una pareja joven contraía matrimonio, generalmente, se marchaba del núcleo familiar para formar una nueva familia en una vivienda independiente. Sin embargo, podía ocurrir que una pareja de recién casados optara por residir en la vivienda de los padres de uno de los miembros del nuevo matrimonio, al menos de manera temporal, hasta disponer de recursos económicos que permitieran tal independencia. Pues bien, cuando esto sucedía, la nueva pareja conyugal generaba un núcleo secundario, en la familia de la que pasaba a formar parte; $y$ a este núcleo secundario se incorporaban también los nacidos tras la celebración del matrimonio. La familia resultante de la unión de varios núcleos es lo que conocemos como familia múltiple (tipo 4 en tabla 1). En ocasiones puede incorporar, además, parientes cercanos y personal doméstico (tipo 4.1.).

Algunas veces, el personal doméstico que trabaja en la casa engloba por sí mismo un núcleo familiar propio, cuando incorpora a la familia de los criados que trabajan para el cabeza de familia. En este

\footnotetext{
${ }^{54}$ García González, “La historia de”, 277-330.
} 
caso, los ejemplos son reducidos: una criada soltera acompańada de su padre viudo, una criada viuda acompańada de un hijo o un criado viudo acompañado de su hija.

En 1827 vivía, en la calle San Antonio, María Palacios, viuda de 64 años. Su posición de señora acaudalada es perceptible porque ejerce como propietaria y cuenta con personal doméstico en el hogar. Trabaja como criado en su casa, Juan Borreguero, un viudo de 60 años y en la vivienda reside también la hija de éste, Francisca Borreguero. Además, esta propietaria acoge en su casa a una sobrina, María Secos, soltera. ${ }^{55}$

En conjunto, las familias múltiples afectan a $0.68 \%$ de las familias estudiadas en esta ciudad. Pero esta escasa presencia de este tipo de hogares se extiende al territorio circundante, pues, la familia múltiple en Extremadura, en la primera mitad del siglo XIX, era de $0.59 \%,{ }^{56}$ así como ocurría en el interior peninsular. Tal es así que en 1840 la ciudad de Cuenca contaba con un $1.6 \%$ de familias múltiples, ${ }^{57}$ que suponían el $0.86 \%$ en la ciudad de Alcaraz en $1787 .{ }^{58}$ Por su parte, en el norte, Liébana contaba con un $12.78 \%$ de familias múltiples en $1752 .{ }^{59}$

Observamos esta diferenciación que apuntábamos al principio del trabajo, donde las familias extensas y múltiples son más frecuentes en el norte peninsular y las familias nucleares en el interior peninsular. Este panorama en el comportamiento familiar a nivel peninsular se debe a cuestiones relacionadas con el modelo hereditario. Durante el Antiguo Régimen, en el norte de España-Galicia, País Vasco y Cataluña- predomina el sistema de heredero único, circunstancia por la cual la complejidad entre los lazos que unen a los miembros del núcleo familiar es mayor, ya que los herederos continúan residiendo en la casa paterna, aún después de haber contraído matrimonio. Sin embargo, en el resto de España predomina el reparto igualitario de la herencia, lo que implica un acceso tem-

\footnotetext{
${ }^{55}$ AMt, Padrón de 1827. Leg. 1004.

${ }^{56}$ Blanco Carrasco, Demografia, 291.

${ }^{57}$ García González, "Las estructuras”, 277-330.

${ }^{58}$ García González, La sierra, 208.

${ }^{59}$ Lanza García, Población, 138-139.
} 
prano a la propiedad o a una parte de la herencia a través de la dote. Como apunta F. García Barriga, estas circunstancias conllevarían una mayor flexibilidad en los matrimonios y en la salida de la casa paterna por parte de los cónyuges. ${ }^{60}$

\section{Las familias sin estructura}

En otras ocasiones, no advertimos en los hogares una estructura familiar definida (tipo 2 en tabla 1), pues nos encontramos con cabezas de familia que residen acompañados de personal doméstico o de individuos aislados, cuya relación de parentesco desconocemos. También se pone de manifiesto la convivencia entre hermanos, principalmente viudos de edad avanzada, pero también de jóvenes solteros que han sufrido la pérdida de los padres. ${ }^{61}$ Hablamos entonces de hogares sin estructura familiar, que suponen $4.34 \%$ de las familias y que desglosamos en cinco subgrupos en la tabla 1 (tipos 2.a-2.e).

La orfandad -junto a la viudez- era la expresión de las dificultades que la muerte ocasionaba a numerosas familias. La desaparición de los progenitores suponía la eliminación de la fuerza de trabajo y, por consiguiente, condena a los descendientes a la pobreza. ${ }^{62}$ Cuando se produce la convivencia entre hermanos huérfanos suele ser el de mayor edad, si es varón, el que pasa a ejercer como cabeza de familia. No obstante, se trata de un modelo de hogar que acabará disolviéndose, como consecuencia de la formación de nuevas familias nucleares por parte de cada hermano, cuando cada uno haya contraído matrimonio. ${ }^{63}$

${ }^{60}$ También el trabajo temporal y las migraciones estacionales proporcionaban a los jóvenes ingresos con los que hacer frente al establecimiento de una nueva familia. Vid. Felicísimo García Barriga, "Estructuras y dinámica familiar en la Extremadura del Antiguo Régimen” (Tesis doctoral dirigida por Miguel Rodríguez Cancho, Universidad de Extremadura, 2007), 123.

${ }^{61}$ En el modelo de familia Fréchère también podían incluirse hermanos, pero su estructura es diferente, pues, es el resultado de asociaciones de varias familias y tienen vocación de continuidad. En cambio, las familias sin estructura tienen un carácter transitorio. Vid. Blanco Carrasco, Demografía, 288-291.

${ }^{62}$ Ibidem, 138-139.

${ }^{63}$ García Barriga, Familia, 128-129. 
En 1824 residían en la calle San Miguel los hermanos Abis: Francisco, María y Juana -de 19, 25 y 9 años respectivamente-; es el varón el que sostiene económicamente a la familia ejerciendo la profesión de sastre. Un año después, en 1825, la hermana mayor abandona la casa familiar, tras haber contraído matrimonio, y establece su nueva familia en la calle Lanchuela. La salida de la casa familiar implica nuevos cambios residenciales, pues, Francisco y Juana Abis se trasladan a calle Nueva. Sin embargo, los cambios continúan en 1827, cuando Juana se traslada a la casa de María Abis. ${ }^{64}$ Esta acogida de los hermanos pequeños por parte de hermanos mayores que, tras haber contraído matrimonio, viven en una casa independiente, solía ser frecuente cuando la orfandad supone un obstáculo para la subsistencia de los hermanos de menor edad. ${ }^{65}$

La formación de hogares sin estructura va a ser una característica común en las poblaciones del norte y del mediodía peninsular, en la segunda mitad del siglo XVIII y primera mitad del siglo xIX. Si en 1752 en Liébana $5.55 \%$ de las familias carecían de estructura determinada, ${ }^{66}$ en la ciudad de Alcaraz en 1787 el porcentaje es menor, un $3 \% .{ }^{67}$ Por su parte, en 1840 la ciudad castellano-manchega de Cuenca contaba con un $6.4 \%$ de familias sin estructura. ${ }^{68}$

Uno de los factores que explicaban la existencia de este tipo de familia es la tenencia de parientes corresidiendo en la vivienda de cabezas de familia que, de otro modo, residirían en solitario, como sucedía con el viudo Ruperto Prieto y su pariente María Liverata en la calle Encarnación. ${ }^{69}$

\section{Las familias de solitarios}

Observamos una última tipología de familias de solitarios. Son hogares en los que residen individuos aislados (tipo 1) de dife-

\footnotetext{
${ }^{64}$ AMT, Padrón de 1824 a 1827. Leg. 1004.

${ }^{65}$ Hernández Bermejo, "Estructuras familiares", 142-145.

${ }^{66}$ Lanza García, Población, 138-139.

${ }^{67}$ García González, La sierra, 208.

${ }^{68}$ García González, "La historia”, 277-330.

${ }^{69}$ AMT, Padrón de 1826. Leg. 1004.
} 
rente sexo y estado civil, que afectan a $11.26 \%$ de las familias estudiadas.

En estos agregados predominan las mujeres en estado de viudedad y generalmente de edad avanzada, las cuales suponen $5.89 \%$ del total (tipo 1.a). La explicación a este fenómeno reside en que, en la sociedad del Antiguo Régimen, las posibilidades de que una mujer contrajese matrimonio superada la edad fecunda eran muy pequeñas, mientras que los hombres podían volverse a casar incluso en edades avanzadas. Con frecuencia la situación económica de las mujeres que enviudaban se complicaba tras el fallecimiento del esposo y muchas de ellas engrosarán las bolsas de pobreza de las comunidades extremeñas. Incapacitadas para el trabajo, muchas estaban abocadas a la mendicidad y el abandono.

La subsistencia de la viuda estará condicionada por la estrechez del mercado de trabajo y por las fallas del sistema de seguridad familiar. En el mejor de los casos, la herencia tras la muerte del marido facilitaría cierta capacidad económica, cuando los bienes aportados por la mujer en la dote no eran suficientes, o bien se habían consumido, dadas las fuertes oscilaciones de la economía doméstica. ${ }^{70}$

La estructura familiar estimada para la Extremadura de la primera mitad del siglo XIX por Blanco Carrasco ${ }^{71}(11.4 \%)$ refleja un volumen de solitarios similar al detectado en la ciudad de Trujillo. Las residencias de individuos en soledad en Trujillo parecen seguir, de este modo, el mismo modelo presente en la región; pero también en otras ciudades del interior peninsular, como en la ciudad de Cuenca, donde en 1844 los hogares integrados por solitarios suponían $9.2 \%$ del total de familias. ${ }^{72}$ De nuevo se produce una continuidad con respecto a la centuria previa, pues, Liébana contaba con un $10.71 \%$ de solitarios en $1752^{73}$ y en 1787 los solitarios en la ciudad de Alcaraz representan $8 \%$ de las familias. ${ }^{74}$

${ }^{70}$ Blanco Carrasco, Demografía, 289-290.

${ }^{71}$ Ibidem, 291.

${ }^{72}$ David S. Reher, Town and Country in Pre-industrial Spain (Cambridge: Cambridge University Press, 1990), 194.

${ }^{73}$ Lanza García, Población, 138-139.

${ }^{74}$ García González, La sierra, 208. 
A partir de una muestra extremeña sobre poblaciones rurales, Blanco Carrasco ${ }^{75}$ advirtió que las familias extensas experimentaron un aumento entre los siglos XVIII y XIX y que ello igualmente es perceptible entre los hogares sin estructura familiar. Precisamente, estas alteraciones en la evolución de las familias extremeñas se extienden a la muestra urbana que hemos analizado; al compararla con poblaciones extremeńas de la centuria anterior.

Observamos que se produce un descenso de solitarios, que si en el siglo XviII constituían el segundo modelo de hogar más numeroso, en Trujillo en los veinte del siglo XIX ocupan el tercer lugar, precedidos del modelo de familia extensa cuyo incremento hemos apuntado. De modo que hemos detectado coincidencias en lo que respecta a la evolución que experimenta el ámbito rural y el ámbito urbano a principios del siglo XIX.

Pensamos que podrían haberse intensificado los mecanismos de solidaridad familiar, a través de los cuales se habría producido la acogida de solitarios en familias nucleares, dando lugar a su transformación en familia extensa; así como una convivencia entre solitarios, tales como las viudas. De hecho, la acogida de mujeres viudas de avanzada edad es el ejemplo más habitual entre los parientes corresidentes acogidos en el hogar en la muestra de Trujillo, generalmente, madres de uno de los cónyuges. Otras veces, el progenitor que es acogido es el padre, en ambos casos el motivo posiblemente derive de la necesidad de asistencia en la vejez. ${ }^{76}$

En 1828, la viuda Antonia Sánchez, pobre y de 83 años, residía en la casa de su hijo, en el barrio del Campillo, con su nuera y su nieto. En cambio, un año después vive en solitario en la casa colindante a la vivienda de su hijo. Por tanto, vemos cómo una familia extensa ha dado paso a una familia nuclear simple y a un hogar similar al integrado por solitarios. En la misma calle pero en distintas casas residían solas otras dos viudas pobres: Rosa Sevillano, de 60 años, y Francisca Cancho, nonagenaria y una de las mujeres más longevas de la ciudad. ${ }^{77}$

${ }^{75}$ Blanco Carrasco, Demografía, 288-292.

${ }^{76}$ Hernández Bermejo, "Estructuras familiares”, 145.

${ }^{77}$ AMT, Padrones de 1828 y 1829. Leg. 1004. Igualmente, hemos observado el trasla- 
Esta variedad de estructuras familiares a la que nos hemos referido se explica, por un lado, porque cuando muere el cabeza de familia en las familias de tipo nuclear conyugal éstas se disuelven; y, por otro, cabe la posibilidad de que los solitarios se integren en otros núcleos. El núcleo del que pasan a formar parte se convierte en una familia extensa, lo cual es frecuente, además, cuando se produce el acogimiento y convivencia de hermanos, sobrinos y viudas. ${ }^{78} \mathrm{Se}$ produce, por tanto, una corresidencia entre distintas generaciones, que se integran en la familia muchas veces para desempeñar una tarea concreta ${ }^{79} \mathrm{y}$ con la finalidad de procurar la subsistencia de los acogidos.

Nos encontramos de este modo ante continuos cambios en la estructura de las familias, influidos por la coyuntura social. Por este motivo, es preciso tener en cuenta que la continuidad de las tipologías presentadas en este trabajo no se va a mantener de manera rígida, puesto que su composición, derivada de fenómenos coyunturales, puede verse modificada y generar una transformación del hogar, identificándolo, así, con una tipología diferente. ${ }^{80}$

\section{LA JEFATURA DEL HOGAR}

El carácter fiscal de las fuentes puede repercutir en la determinación de la cabeza del hogar, pues, se asume como parte integrante al contribuyente. Sin embargo, la corresidencia no necesariamente ha de girar en torno a su figura, es decir, la cabeza de familia desde el punto de vista "productivo" podría no serlo desde el punto de vista "familiar". Por ejemplo, encontramos parientes de la esposa que residen en el hogar, mientras que el cabeza de familia es el esposo. ${ }^{81}$

do de residencia de una mujer viuda a la casa de una hermana también viuda que hasta entonces vivía sola.

${ }^{78}$ Blanco Carrasco, Demografía, 207-228.

${ }^{79}$ Ibidem, 290.

${ }^{80}$ Hernández Bermejo, "Estructuras familiares”, 142-145.

${ }^{81}$ García Barriga, Familia, 122. 


\section{El estado civil y el sexo del cabeza de familia}

Entre 1824 y 1829, las características que conciernen al estado civil y a la distribución por sexos de los cabezas de familia situados al frente de un hogar no parecen sufrir grandes alteraciones entre unos años y otros.

La importancia del matrimonio se pone de manifiesto cuando observamos que tres de cada cuatro cabezas de familia están casados (75\%) (véase tabla 2). La viudez envuelve a $18 \%$ de los hogares que se hacen responsables de una familia, que ha sufrido la fragmentación del hogar; mientras que los solteros al frente de una jefatura se reducen a $5 \%$.

TABLa 2. Distribución de los cabezas de familia por estado civil. Trujillo (1824-1829). Valores relativos (porcentajes)

\begin{tabular}{lrrrrrrr}
\hline Estado civil & 1824 & 1825 & 1826 & 1827 & 1828 & 1829 & $\begin{array}{c}\text { Toda la } \\
\text { muestra }\end{array}$ \\
\hline Casados & 77.29 & 74.74 & 74.5 & 75.9 & 77.38 & 75.03 & 75.8 \\
Solteros & 3.8 & 6.31 & 6.37 & 6.18 & 4.96 & 5.17 & 5.47 \\
Viudos & 18.89 & 18.94 & 19.12 & 17.91 & 17.64 & 19.79 & 18.72 \\
\hline $\begin{array}{l}\text { Total cabezas } \\
\text { de familia }\end{array}$ & 100 & 100 & 100 & 100 & 100 & 100 & 100 \\
\hline
\end{tabular}

Fuente: las mismas que en la tabla anterior. Elaboración propia.

Los hombres: casados, viudos y solteros

En la ciudad de Trujillo, $85.46 \%$ de las familias están encabezadas por varones, de los cuales $74.99 \%$ figuran como casados; mientras que el volumen de viudos y solteros al frente de un hogar se reduce a $6.84 \%$ y $3.63 \%$ respectivamente. En una ciudad en la que predomina el modelo de familia nuclear, el matrimonio se convierte "en el principal vehículo de acceso" a la jefatura del hogar; de ahí que predomine el número de hombres casados al frente de un hogar. ${ }^{82}$

${ }^{82}$ Blanco Carrasco, Demografía, 298. 
Estos resultados se aproximan a los estimados por Blanco Carrasco para Extremadura a mediados del siglo xviII y primera mitad del siglo XIX, si bien su representatividad es menor que la que se da en Trujillo, con cifras que rondan $60 \%$ de cabezas de familia varones casados. ${ }^{83}$ Asimismo, los estudios realizados por Hernández Bermejo ${ }^{84}$ permiten comparar las estrategias familiares desarrolladas en Trujillo con otra de las ciudades de la Alta Extremadura, la ciudad de Coria, cuyas familias contaban con varones en la jefatura del hogar en un $80 \%$ de los casos. Aunque se trata de datos de cronología anterior a la de nuestro estudio, pues, se analizan los años centrales del siglo XviII, manifiestan la continuidad del modelo de jefatura de hogar predominante a finales del Antiguo Régimen.

En definitiva, el modelo de jefatura de hogar de hombre casado es consecuencia de un bajo índice de celibato definitivo en Trujillo, donde permanecer soltero no era lo más habitual, tal y como sucede en el Antiguo Régimen en Extremadura y otros territorios del interior y sur peninsular. ${ }^{85}$ Asimismo, la viudedad masculina en muchos casos es transitoria, ya que solía finalizar con la celebración de un matrimonio en segundas nupcias habitualmente con mujeres más jóvenes. ${ }^{86}$

Las mujeres: viudas, solteras y casadas

Las mujeres al frente de una familia constituyen $14.53 \%$ de toda la muestra integrada por ambos sexos. Su posición como responsables del mantenimiento del hogar es visible varias décadas antes en otros

${ }^{83}$ Ibidem.

${ }^{84}$ Concretamente esta autora analiza el hogar y las estructuras familiares en la ciudad de Coria, a partir del análisis de los informes relativos a la ciudad, para la elaboración del Catastro de Ensenada en 1753, así como las Comprobaciones realizadas en 1761. Hernández Bermejo, "Estructuras familiares", 135-142.

${ }^{85}$ Rowland estima para la Extremadura de finales del siglo xvin porcentajes de celibato definitivo de 12.7 y 8.9 en varones y mujeres respectivamente. Vid. Robert Rowland, Sistemas matrimoniales, 95.

${ }^{86}$ En Extremadura la frecuencia de matrimonios entre viudos y jóvenes solteras era el más común, con ello se pretendía asegurar la descendencia así como la supervivencia de la mujer a causa de los sucesivos partos. Vid. José Pablo Blanco, Demografía, 223. 
núcleos urbanos del interior peninsular, a partir de trabajos que han desvelado una presencia de las mujeres en la jefatura del hogar similar a la de nuestro estudio. ${ }^{87}$

En Trujillo, entre las mujeres que encabezan una familia, predominan aquellas que han sufrido la pérdida de sus esposos; suponen $11.87 \%$ y se sitúan en segundo lugar después de los varones casados. ${ }^{88}$

El significativo volumen de mujeres viudas que forman parte del grupo de familias integradas por un solo miembro no responde únicamente a la defunción de la pareja conyugal, sino al sexo del que sobrevive. Es decir, aunque los hombres también sufren la pérdida de sus respectivas parejas, el número de viudos que ocupan cabeceras de hogar es mucho más reducido. Como ya hemos mencionado, esto se debe a que los viudos varones vuelven a contraer matrimonio, frente a la dificultad con la que se encuentran las mujeres para contraer nuevas nupcias, sobre todo, a partir de cierta edad ${ }^{89}$ En el caso de las mujeres viudas, a partir de los 40 años era más complicado que volvieran a contraer matrimonio, lo cual por lo general las convierte en pobres debido a las implicaciones económicas que conlleva la pérdida del marido. ${ }^{90}$

Dicho acceso de la mujer a la jefatura del hogar tras la muerte del esposo, consecuencia del ciclo vital de la pareja, en ocasiones se ve alterado por el relevo de la mujer en la posición de cabeza de familia, que pasaría a ser ocupada por un hijo varón o por el marido de una de las hijas. ${ }^{91}$

De lo más interesante es la trayectoria familiar de la viuda Catalina Ximénez: Hasta 1827 esta viuda de 60 años es cabeza de familia

${ }^{87}$ En 1787, en la ciudad de Alcaraz las mujeres cabezas de hogar suponían $15.9 \%$ de los hogares. García González, La sierra, 213-214.

${ }^{88}$ En la muestra rural extremeña de 1829 analizada por García Barriga, las mujeres viudas que ocupan cabeceras de hogar es de $13.43 \%$, de modo que su representatividad es mayor en los núcleos rurales que en Trujillo. García Barriga, Familia, 148-149.

${ }^{89}$ José Pablo Blanco Carrasco, "Dinámicas familiares en el entorno rural español: la ciudad de Trujillo a finales del Antiguo Régimen", en Familles, pouvoirs, solidarités. Domaine mediterranéen et hispano-américain (XV-XX siècle), ed. Barbazza y Heusch, 101-104. Montpellier: Presses Universitaires de la Méditerranée PULM, 2002.

${ }^{90}$ Blanco Carrasco, Demografía, 207-228.

${ }^{91}$ Blanco Carrasco, "Dinámicas familiares", 101-104. 
de un hogar en el que residen sus dos hijos solteros, Domingo y Teresa Valle; el varón de profesión barbero. A dos casas de distancia se había trasladado dos años antes su hija Juana, tras haber contraído matrimonio con un zapatero. Un año después, ya sólo reside con Catalina su hijo Domingo, pues, Teresa ha contraído matrimonio con un sastre, con el que se ha marchado a vivir a la casa de al lado. En 1829, Juana y su esposo ya tienen dos hijos y acogen en la vivienda a su hermano Domingo y a una viuda de 65 años, cuyo parentesco con el matrimonio desconocemos, pero que podría tratarse de la madre del esposo. Ese mismo año, Catalina continúa siendo cabeza de familia de la misma casa en la calle Sillería, donde había vivido a lo largo de estos años, pero donde ahora residía en soledad. ${ }^{92}$

En lo que respecta al volumen de mujeres solteras responsables de una familia, hemos calculado que en Trujillo es de apenas $1.8 \%$ (véase tabla 3). La situación de indefensión económica y jurídica en la que se encontraba la mujer durante el Antiguo Régimen explica los bajos porcentajes de mujeres solteras al frente de la jefatura del hogar; en la medida en que contraer matrimonio les garantizaría una seguridad y una estabilidad económica y social que de otra manera, en la mayor parte de los casos, no sería posible.

La "evasión" del celibato definitivo entre el sexo femenino también es visible en otros centros urbanos de la Alta Extremadura durante el siglo XviII. El volumen de mujeres solteras caurienses que figuran como cabezas de familia entre 1753 y 1761 oscilaba entre $2.2 \%$ y $2.4 \%$ en uno y otro año. ${ }^{93}$ Asimismo, los valores descienden en la muestra rural extremeña de 1829 analizada por García Barriga $^{94} \mathrm{y}$ en la que $0.67 \%$ de los hogares están encabezados por mujeres solteras.

En ocasiones, ante la ausencia temporal del marido, la mujer ocupa la jefatura del hogar, para abandonarla al regreso del esposo. De manera que se producen cambios en la posición que ejerce el cabeza de familia en un mismo hogar. Hemos observado que el vo-

\footnotetext{
${ }^{92}$ AMT, Padrones de 1824 a 1829. Leg. 1004.

${ }^{93}$ Hernández Bermejo, "Estructuras familiares”, 139-140.

${ }^{94}$ García Barriga, Familia, 148-149.
} 


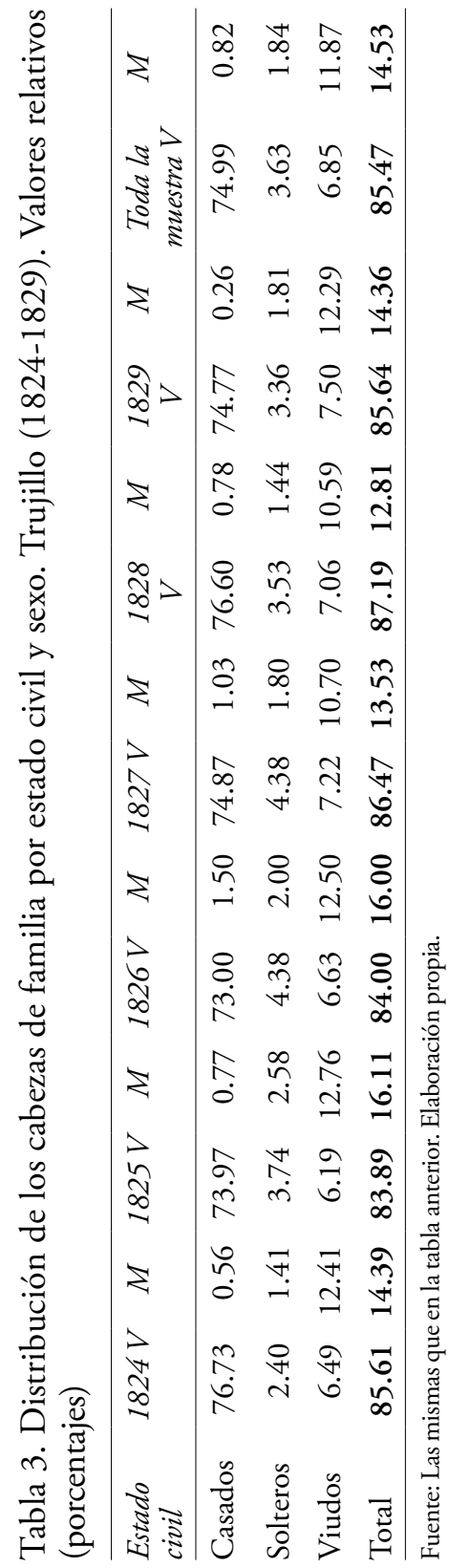


lumen de casadas cabezas de familia en esta ciudad es inferior al uno por ciento $(0.8 \%) .^{95}$

En 1824, Bárbara Sanabria, de 30 ańos, vivía en la calle Domingo Ramos junto a su hija de un año y su esposo, Francisco Ojalvo. Era el marido quien ejercía de cabeza de familia hasta que, entre los ańos 1825 y 1827, el esposo no aparece como residente en la ciudad. Entonces Bárbara, cuyo estado civil continúa siendo el de casada, reside con su hija en la misma calle, pero ahora ejerce la jefatura del hogar y además figura como pobre. La precaria situación económica en la que se encuentra explica que, en 1828 , ambas pasen a formar parte de la familia de una viuda labradora de la ciudad, residente en la misma calle y para la cual Bárbara Sanabria trabajará como criada, por lo que ya no figura como cabeza de familia. El regreso del esposo en 1829 supondrá su salida del hogar en el que trabajaba, para constituir nuevamente su propia familia, ya con el esposo al frente del hogar. ${ }^{96}$

En última instancia, la escasa existencia de mujeres jefas de hogar en Trujillo con respecto al volumen de varones se debe al modelo de familia nuclear y sistema de matrimonio neolocal principalmente y a los bajos índices de soltería, que eran consecuencia de la mentalidad de la época, en la que quedarse soltera, por un lado, no estaba muy bien visto, y, por otro, haría difícil la supervivencia de aquellas mujeres que carecieran del patrimonio necesario para ser independientes económicamente, realidad que afectaba a una gran parte de las mujeres. Por su parte, la segunda nupcialidad suponía para muchas viudas una salida a la pobreza.

Asimismo, observamos que en las jefaturas de hogar femeninas se dan redes de solidaridad de género, donde se acogen hermanas viudas y solteras por parte de estas mujeres, que dan lugar a hogares

\footnotetext{
${ }^{95}$ Nos situamos en un contexto en el que el derecho patrimonial castellano prácticamente separa a la mujer de la jefatura del hogar. Su pequeńa representatividad como cabeza de familia puede esconder, a su vez, una dependencia económica de sus hijos o parientes masculinos, cuando no vivían en la indigencia. Es decir, aunque figuran como cabezas de familia, no necesariamente tenían que ser ellas las que mantuvieran económicamente el núcleo familiar. Blanco Carrasco, Demografía, 298.

${ }^{96}$ AMT, Padrones de 1824 a 1829. Leg. 1004.
} 
formados por hermanas adultas. Un ejemplo ilustrativo del acogimiento y de la protección familiar y económica que ejercían algunas viudas es el de la viuda propietaria Ana Quijada - de 63 ańos- que reside en una casa de la calle Nueva, donde es cabeza de familia y convive con su hermana María Manuela Quijada, también viuda, pero que figura como pobre, al contrario que su hermana mayor, la cual además tiene en su casa a una criada. ${ }^{97}$

\section{La edad del cabeza de familia}

La edad media repercute en el modelo familiar predominante en cada núcleo, en la medida en que la supervivencia durante más tiempo de los esposos tiende a modificar los regímenes nucleares en extensos. Se produce la absorción de generaciones ascendentes por parte de los cada vez más numerosos hijos que sobreviven a sus padres. ${ }^{98} \mathrm{El}$ promedio de edad del cabeza de familia en la muestra trujillana que hemos analizado es de 42.49 ańos.

El modelo de familia extremeño en la segunda mitad del siglo XVIII y primera mitad del siglo XIX manifiesta una media de edad en la jefatura del hogar muy próxima a la de los núcleos analizados. En el ańo 1825 , Coria presenta una media de 42 ańos, ${ }^{99}$ mientras que en 1752 la muestra de núcleos rurales analizada por García Barri$\mathrm{ga}^{100} \mathrm{y}$ que engloba a las poblaciones cacereñas de Brozas, Casar, Malpartida, Navas y Arroyo es de 41.18 años.

$\mathrm{Si}$ calculamos la edad media por sexos y estado civil observamos datos muy interesantes. El planteamiento que apuntábamos acerca de la mujer cabeza de familia viuda y de avanzada edad se confirma cuando observamos una diferencia de diez ańos entre hombres y mujeres cabezas de familia, siendo la mujer que ocupa la cabecera del hogar de 52 años y el hombre de 41 años. Por tanto, la media de edad de la mujer que se sitúa al frente de un hogar se sitúa por enci-

\footnotetext{
${ }^{97}$ AMT, Padrón de 1828. Leg. 1004.

${ }^{98}$ García Barriga, Familia, 300.

${ }^{99}$ Blanco Carrasco, Demografía, 287-301.

${ }^{100}$ García Barriga, Familia, 149.
} 
ma de la media regional, mientras que la edad de los hombres coincide con los resultados obtenidos en las muestras analizadas en Extremadura.

La edad media de los hombres casados condiciona indudablemente los resultados globales obtenidos, pues, como se ha señalado, tres de cada cuatro cabezas de familia están casados; así, pues, los hombres que han contraído matrimonio y se sitúan al frente de un hogar tienen de media 40 años, mientras que las mujeres casadas en su misma situación, aunque representan un porcentaje muy bajo, son aún más jóvenes, pues, cuentan con un promedio de edad de 30 años. Entendemos, por tanto, que serán la soltería femenina y, especialmente, la viudedad los factores que contribuyen al aumento de edad entre las mujeres responsables de espacios domésticos. De hecho, las viudas superan los 50 años al igual que sucede con los hombres viudos (54 años y 51 años respectivamente), son las mujeres que han sufrido la pérdida del esposo las de mayor edad entre todos los cabezas de familia y, además, algunas de ellas son ancianas. Por poner un ejemplo, en 1829, el viudo de mayor edad era Manuel Molano de 76 años, mientras que las viudas más ancianas eran la octogenaria Isabel Rodríguez y la nonagenaria Francisca Cancho. ${ }^{101}$ Casualmente los tres encabezaban familias de solitarios.

Asimismo, en lo que respecta a los solteros, mujeres y hombres protagonizan generalmente una soltería que probablemente será definitiva, ya que en ambos casos supera los 40 años ( 43 años y 46 años respectivamente). Muchos de ellos no llegarán a casarse nunca, como le sucedería a la octogenaria Rosa Varela, que vivía sola y además era pobre; y al septuagenario don Manuel Cabelludo, que también residía solo, pero en este caso contaría con los ingresos de su oficio como administrador y apoderado (véase gráfica 1).

En cualquier caso, los resultados globales obtenidos del análisis de los modelos de familia, así como de los cabezas de familia en la muestra estudiada, nos hacen pensar que los hogares de Trujillo se rigen bajo las mismas pautas seguidas por familias de otras localida-

${ }^{101}$ AMT, Padrón de 1829. Leg. 1004. 


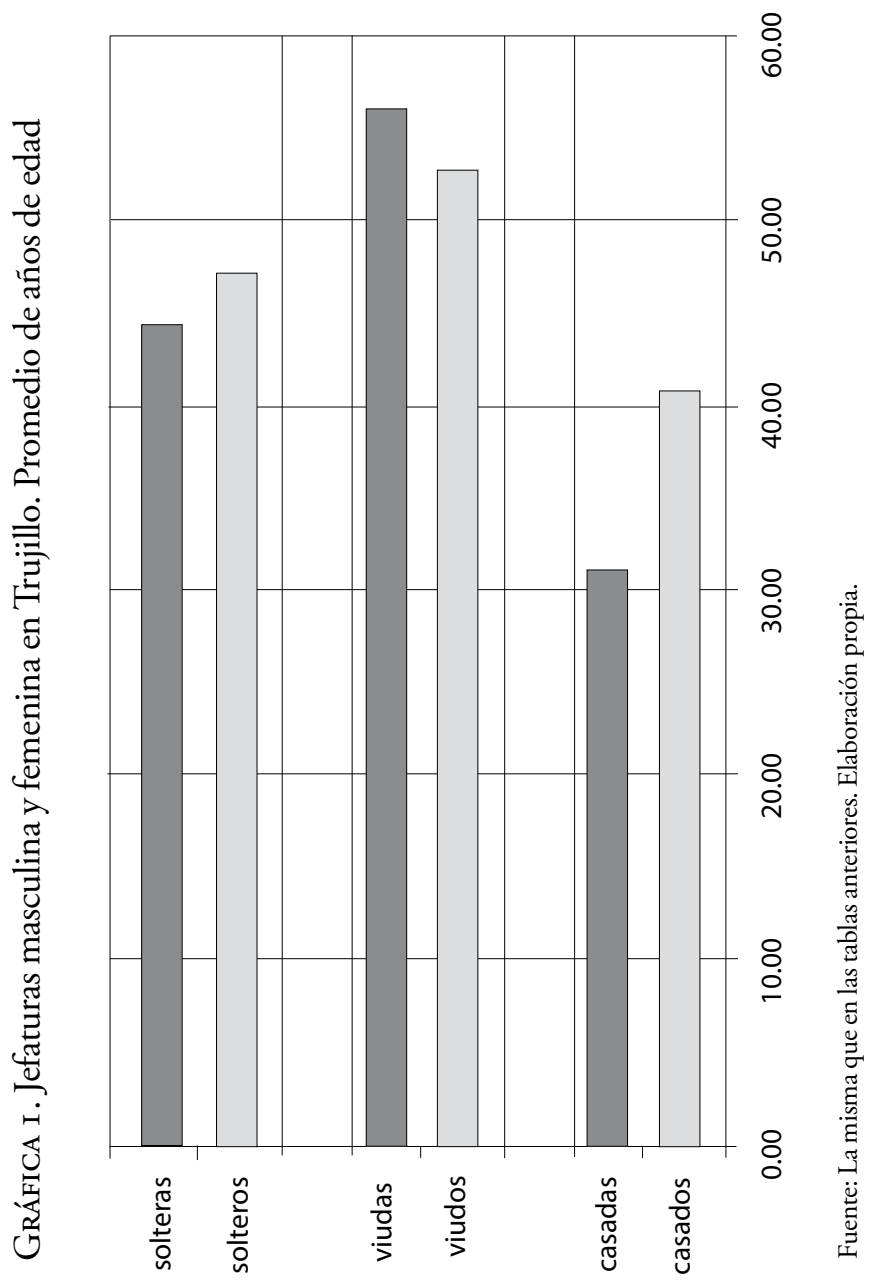


des extremeñas y también del interior peninsular, que presentan datos similares, a mediados del siglo xviII y en la primera mitad del siglo XIX. ${ }^{102}$

\section{Conclusiones}

Desde una perspectiva demográfica, aplicada a la Historia de la Familia, hemos ofrecido una visión del comportamiento familiar seguido en los hogares de la ciudad de Trujillo, en el sexenio comprendido entre 1824 y 1829 . Concretamente, nuestro estudio ha abarcado dos vertientes: por un lado, el modelo de familia que caracteriza a los hogares y que se mide a partir de los miembros de la unidad residencial; $y$, por otro, el rol director del cabeza de familia en la jefatura del hogar.

En lo que respecta a los modelos de familia, hemos observado que las estrategias familiares conducen a un predominio de las familias constituidas por padres e hijos. No obstante, este modelo de familia nuclear simple, en ocasiones se ve alterado, como consecuencia de la puesta en marcha de mecanismos de solidaridad familiar que conducen a la acogida en el hogar de parientes cercanos. Por consiguiente, se produce una transformación de familia nuclear simple en familia extensa, de la cual también formará parte el personal doméstico, con el que cuentan, principalmente, los grupos acomodados. Tan sólo de manera excepcional aparecen las familias múltiples, a las que se incorpora un segundo núcleo familiar.

Otras veces, el fallecimiento de uno de los cónyuges, unido a la salida del hogar de aquellos hijos que han contraído matrimonio, deriva en una disolución del núcleo familiar, que explica la presencia de un significativo volumen de solitarios al frente del hogar, principalmente, mujeres en estado de viudedad. Asimismo, también se forman hogares cuya composición interna no deja ver un modelo de familia claramente definido, puesto que las relaciones de parentesco entre sus componentes hacen que carezca de estructura.

${ }^{102}$ Blanco Carrasco, Demografía, 287-301. 
En cuanto a la jefatura del hogar, parece claro el predominio del hombre casado y de mediana edad como responsable fiscal del agregado familiar. Por lo general, la mujer toma protagonismo sólo cuando carece de la figura paterna o marital en la casa, es entonces cuando adquiere el rol de cabeza de un núcleo familiar, del que se hace responsable. La escasa existencia de mujeres jefas de hogar en Trujillo se debe al sistema de matrimonio neolocal predominante en la época, que facilitaba el acceso al matrimonio y al modelo de familia nuclear, y provocaba a su vez bajos índices de soltería. Asimismo, eran las viudas que habían finalizado la etapa fértil las que tendrían mayores dificultades para contraer nuevamente matrimonio. $\mathrm{Si}$ bien, llama poderosamente la atención la soledad de los viudos y solteros más ancianos, para algunos de los cuales no observamos el desarrollo de solidaridades familiares, pese a encontrarse en una situación de pobreza.

En definitiva, el análisis de la composición interna de las familias pone de manifiesto la manera en la que éstas se amoldan a las circunstancias particulares de cada núcleo. A veces se deshacen familias y otras veces se rehacen pero, en cualquier caso, los cabezas de familia, acostumbrados a situaciones cambiantes, activan mecanismos capaces de ofrecer soluciones a contextos de crisis de todo tipo: desde la merma del núcleo familiar que supone la muerte de uno de los miembros de la pareja conyugal o de uno de los vástagos, hasta la ampliación de la familia que implica el nacimiento de un hijo, o la acogida de un pariente joven o anciano que necesita protección y cobijo.

\section{Agradecimientos}

Este trabajo ha sido financiado gracias a la concesión de una beca para la Formación de Profesorado Universitario (FPU) por el Ministerio de Educación, Cultura y Deporte (MECD). El trabajo se inserta en el marco del Proyecto de Investigación "Familia y comunidad rural: mecanismos de protección comunitaria en el interior peninsular (ss. XVIII-1900)" (con referencia HAR2013-48901-C6-5-R), Plan Nacional I+D del MINECO, cuyo Investigador principal es José Pablo Blanco Carrasco. 


\section{BIBLIOGRAFÍA}

Arbaiza Vilallonga, Mercedes. Familia, trabajo y reproducción social: una perspectiva microhistórica de la sociedad vizcaina a finales del Antiguo Régimen. Bilbao: Universidad del País Vasco, 1996.

Blanco Carrasco, José Pablo. Demografía, familia y sociedad en la Extremadura moderna, 1500-1860. Cáceres: Universidad de Extremadura, 1999.

, "Dinámicas familiares en el entorno rural español: la ciudad de Trujillo a finales del Antiguo Régimen”. En Familles, pouvoirs, solidarités. Domaine mñediterranéen et hispano-américain (XV-XX siècle), ed. Barbazza y Heusch 101-110. Montpellier: Presses Universitaires de la Méditerranée PULM, 2002.

CASEY, James y Bernard VinCENT. "Casa y familia en la Granada del Antiguo Régimen”. En La familia en la España mediterránea. Siglos XV-XIX, coord. James Casey et al., 172-211. Barcelona: Crítica, 1987.

Chacón Jiménez, Francisco. Historia social de la familia en España. Alicante: Instituto de cultura "Juan Gil-Albert", 1990.

"Familia y hogar en la sociedad española: mitos y realidades históricas", en La familia en la historia, coord. Francisco Javier Lorenzo Pinar, 121-134. Salamanca: Universidad de Salamanca, 2009.

García BARriga, Felicísimo. Estructuras y dinámica familiar en la Extremadura del Antiguo Régimen. Tesis Doctoral dirigida por M. Rodríguez Cancho,Universidad de Extremadura, 2007. Familia y sociedad en la Extremadura rural de los tiempos modernos (siglos XVI-XIX). Cáceres: Universidad de Extremadura, 2009.

García González, Francisco. La sierra de Alcaraz en el siglo XVIII: población, familia y estructura agraria. Albacete: Instituto de Estudios Albacetenses “Don Juan Manuel”, 1998a.

"Introducción. De la Tierra a la Historia de la Familia en la Espańa meridional”. En Tierra y familia en la España meridional. Siglos XIII-XIX, ed. Francisco García Gonzalez, 9-21. Murcia: Universidad de Murcia, 1998b. 
. "Labradores, jornaleros y sirvientes en la sierra. Organización doméstica y ciclo de vida (Alcaraz, 1753-1787)”. En Tierra y familia en la España meridional. Siglos XIII-XIX, ed. Francisco García Gonzalez, 155-192. Murcia: Universidad de Murcia, 1998c.

. "La historia de la familia en el interior castellano: estado de la cuestión y esbozo bibliográfico". En La historia de la familia en la Península Ibérica, siglos XVI-XIX: balance regional y perspectivas. Homenaje a Peter Laslett. ed. Francisco García Gonzalez, 277330. Cuenca: Universidad de Castilla La Mancha, 2008.

- "Las estructuras familiares y su relación con los recursos humanos y económicos”. En Familias. Historia de la sociedad española (del final de la Edad Media a nuestros dias), dir. Francisco Chacón y Joan Bestard, 159-254. Madrid: Cátedra, 2011.

García PÉrez, Juan. "La economía extremeña durante la crisis del antiguo régimen y el tiempo del liberalismo clásico (18081874)". Revista de Estudios Extremeños LXIX(I) (2013): 212-219.

GARrido Arce, Estrella, "Tener o no tener en 1791. Estructuras familiares y tenencia de la tierra en la Huerta de Valencia, siglo XVIII". En Tierra y familia en la España meridional. Siglos XIII-XIX, ed. Francisco García Gonzalez, 193-223. Murcia: Universidad de Murcia, 1998.

Henry, Louis. Manual de demografía histórica. Barcelona: Crítica, 1983.

Hernández Bermejo, María Ángeles. "Estructuras familiares y sistemas de transmisión patrimonial en Extremadura. La ciudad de Coria en el siglo xviII". En Tierra y familia en la España meridional. Siglos XIII-XIX, ed. Francisco García Gonzalez, 133-153. Murcia: Universidad de Murcia, 1998.

Hernández López, Carmen. "La casa en La Mancha Oriental a finales del Antiguo Régimen". Cuadernos de Historia Moderna (38) (2013): 93-119.

Hurtado Martínez, José. "Familia y propiedad: análisis del hogar y de la estructura de la propiedad en Lorca (1771)”. En Familia y sociedad en el Mediterráneo Occidental. Siglos XV-XIX, ed. Francisco Chacón Jiménez, 301-334. Murcia: Universidad de Murcia, 1987. 
Lanza García, R., Población y familia campesina en el Antiguo Régimen. Liébana, siglos XVI-XIX. Santander: Universidad de Cantabria, 1988.

LASLETT, Peter. "La famille et le ménage: approches historiques". Annales, ESC. (4-5) (1972): 847-872.

. "Introduction: the History of the Family". En Household and Family in Past Time, ed. Peter Laslett y Richard Wall, 1-90. Cambridge: Cambridge University Press, 1974.

LÁzAro Ruiz, Mercedes. La población de la ciudad de Logroño durante el Antiguo Régimen. Logroño: Instituto de Estudios Riojanos, 1994.

Martín Galán, Manuel. "La población de Madrid y Castilla-La Mancha según el censo de Floridablanca”. En La población española en 1787, II Centenario del censo de Floridablanca, coord. Francisco Chacón Jiménez et al., 157-192. Madrid: Instituto Nacional de Estadística, 1992.

Mikelarena Peña, Fernando. "Estructuras familiares en España y en Navarra en los siglos XVIII-XIX: factores etnoculturales, diferenciación socioeconómica y comportamientos estratégicos". En Actas II Congreso Italo-Ibérico de Demografía Histórica. Savona: 1992, 20-33.

Montojo Montojo, Vicente. "Rasgos de la estructura familiar en Fuente Álamo (Murcia) a mediados del siglo Xvin”. En Casa, familia y trabajo. Actas del Congreso Internacional Historia de la Familia. Una nueva perspectiva sobre la sociedad europea, ed. Francisco Chacón Jiménez y Llorenç Ferrer i Allós, 289-295. Murcia: Universidad de Murcia, 1997.

PÉrez García, José Manuel. "Familias y hogares en Galicia y en la Cornisa Cantábrica durante el Antiguo Régimen”. En Historia de la familia en la Peninsula Ibérica: balance regional y perspectivas. Homenaje a Peter Laslett, coord. Francisco García González, 57-84. Cuenca: Universidad de Castilla-La Mancha, 2008.

Pizarro Gómez, Francisco Javier. Arquitectura y urbanismo en TrujiIlo (siglos XVIII y XIX). Cáceres: Universidad de Extremadura. 1987. Reher, David S. Town and Country in Pre-Industrial Spain. Cambridge: Cambridge University Press, 1990. 
Rowland, Robert. "Sistemas matrimoniales en la Península Ibérica (siglos XVI-XIX). Una perspectiva regional”. En La demografia histórica en España, ed. Vicente Pérez Moreda y David S. Reher, 72-137. Madrid: El Arquero, 1988.

Sánchez Arroyo, Fernando. "Estructura político-institucional de Extremadura (1808-1874)". Revista de Estudios Extremeños $\operatorname{LXIX(I)~(2013):~141-206.~}$

Sancho Alguacil, Remedios. "Población y estructura familiar en una comunidad de la Vega Alta del Segura: Cieza durante el siglo XVIII". En Familia y sociedad en el Mediterráneo Occidental. Siglos $X V$-XIX, ed. Francisco Chacón Jiménez, 279-300. Murcia: Universidad de Murcia, 1987.

Tovar Pulido, Raquel. "Estructura de la familia en la ciudad de Trujillo a finales del Antiguo Régimen (1824-1825)", en XLIII Coloquios Históricos de Extremadura: dedicados a Luisa de Carvajaly Mendoza en el IV Centenario de su muerte, ed. VV. AA. Trujillo, del 22 al 28 de septiembre de 2014, 2015, 869-886.

"Mercado laboral en un núcleo urbano de la España de finales del Antiguo Régimen: La ciudad de Trujillo", Chronica Nova: Revista de Historia Moderna de la Universidad de Granada. Ejemplar dedicado a: Relaciones entre la Monarquía Hispánica y la Roma Pontificia (siglos xvi y xviI) (42) (2016) 367-397. 